\title{
Comparison of Magnetic and Mössbauer Results Obtained for Palaeozoic Rocks of Hornsund, Southern Spitsbergen, Arctic
}

\author{
K. Szlachta ${ }^{a, *}$, K. Michalski ${ }^{b}$, K. BrzózkA ${ }^{c}$, B. Górka ${ }^{c}$ \\ AND J. GAEA̧ZKA-FRIEDMAN ${ }^{a}$ \\ ${ }^{a}$ Faculty of Physics, Warsaw University of Technology \\ Koszykowa 75, 00-662 Warszawa, Poland \\ ${ }^{b}$ Institute of Geophysics, Polish Academy of Sciences \\ Księcia Janusza 64, 01-452 Warszawa, Poland \\ ${ }^{c}$ Department of Physics, Technical University of Radom \\ Malczewskiego 29, 26-600 Radom, Poland
}

\begin{abstract}
This analysis was performed as a part of the palaeomagnetic project focused on the reconstruction of the palaeogeographic position of the Svalbard Archipelago and adjacent crustal units (European Arctic) in the Palaeozoic and Mesozoic. Three rock formations - Cambrian, Devonian and Carboniferous were sampled in the area of Hornsund, southern Spitsbergen. The main aim of the presented study is to identify ferromagnetic minerals (sensu lato) - the carriers of the natural remanent magnetisation in the investigated rocks. A wide range of magnetic methods were used: the Lowrie tests, unblocking temperatures determinations and the measurement of coercivity spectra as well as the Mössbauer studies. In Devonian and Carboniferous samples all applied methods indicate the domination of the hematite natural remanent magnetisation carrier. In Cambrian rocks magnetic measurements reveal a mixture of ferromagnetic (sensu lato) minerals with varying coercivities and unblocking temperatures. The Mössbauer data improve the identification, suggesting that in Cambrian rocks the carrier of the dominating natural remanent magnetisation component is maghemite.
\end{abstract}

PACS numbers: 91.25.F-

\section{Introduction}

The identification of the ferromagnetic (sensu lato) minerals that are the carriers of palaeomagnetic directions is important part of palaeomagnetic studies.

*corresponding author; e-mail: szlachta@list.pl 
Assessing the mineralogy of ferromagnetic minerals we are able to describe the geochemical conditions in which the natural remanent magnetisation (NRM) was formed and to evaluate the age of the observed palaeomagnetic direction. However, similar or even overlapping maximum unblocking temperatures $\left(T_{\mathrm{ub} \max }\right)$ and coercivity spectra of the main ferromagnetic (sensu lato) minerals often make identification uncertain. From this point of view the Mössbauer measurements seem to be excellent complementary studies to magnetic investigations.

\section{Materials and methods}

Samples have been taken from fresh, unweathered, in situ rocks exposed in the area of Hornsund. Three rock formations have been sampled:

1. Cambrian limestones of the Slaklidalen Formation,

2. Devonian sandstones of the Marietoppen Formation,

3. Carboniferous sandstones of the Hyrnefjellet Formation.

The following methods have been applied to identify ferromagnetic (in situ) mineralogy.

\subsection{Magnetic study}

2.1.1. Determination of decay curves of saturation isothermal remanent magnetisation (SIRM), according to the Kruczyk and Kadziatko-Hofmokl (1976) procedure

19 cylindrical specimens (diameter $7 \mathrm{~mm}$, height $9 \mathrm{~mm}$; 6-7 from each rock formation) were magnetised in a field $7 \mathrm{~T}$ using a MMPM-10 pulse magnetiser. Subsequently they were heated up to $700^{\circ} \mathrm{C}$ in field free space. The maximum unblocking temperatures of ferromagnetic (sensu lato) minerals have been identified on demagnetisation curves (Fig. 1a, 2a) [1].

2.1.2. IRM curves determinations and Lowrie test according to procedure described by Lowrie (1990)

59 cylindrical specimens (diameter $20 \mathrm{~mm}$, height $22 \mathrm{~mm}$; 16-21 from each rock formation) were investigated. At first, during isothermal remanent magnetisation (IRM) acquisition, the specimens were subjected to gradual magnetisation along the $z$ axis at room temperature up to $2.9 \mathrm{~T}$. Next the samples were magnetised along two other perpendicular axes in fields of $0.4 \mathrm{~T}$ along the $y$ axis and of $0.12 \mathrm{~T}$ along the $x$ axis. Magnetisation was performed in a MMPM-10 pulse magnetiser. At the final stage of the experiment samples were subjected to stepwise thermal demagnetisation in a field free magnetic furnace (made by Magnetic Measurements, Great Britain). After each magnetisation and demagnetisation step IRM of the samples were measured using a superconducting quantum interference device (SQUID) made by 2g, USA. Saturation fields of specimens are given on IRM plots (Fig. 1d, 2d). From thermomagnetic remanent Lowrie curves we were able to estimate the content of ferromagnetic (sensu lato) phases characterised by different unblocking temperatures and coercivities (Fig. 1b, 2b) [2]. 

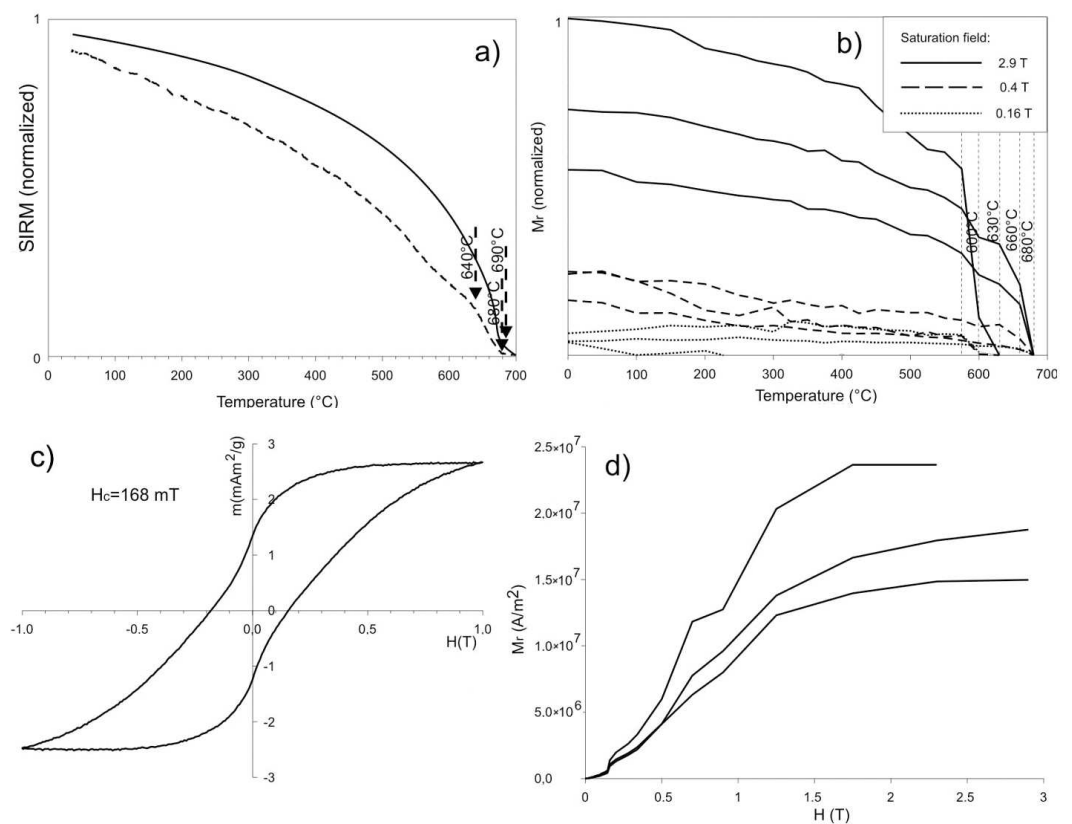

Fig. 1. Examples of results of magnetic investigations - Devonian Marietoppen Fm and Carboniferous Hyrnefjellet Fm: (a) decay curves of SIRM - on the first solid curve ferromagnetic minerals existing in rock are identified, on the second dashed curve ferromagnetic minerals which appeared during first heating are shown. (b) Lowrie test visible dominating high coercivity fraction, (c) hysteresis loop typical of high coercivity mineral - probably hematite with distinct wasp-waist shape typical of mixtures of ferromagnetic minerals; (d) IRM curves; abbreviations: $m$ - magnetic moment, $M_{\mathrm{r}}-$ remanent magnetization, $H$ - applied field.

\subsubsection{Determinations of hysteresis loop parameters}

Hysteresis loops have been measured for 25 specimens (irregular pieces of rocks with a maximum diameter of $1 \mathrm{~mm}$, from 6 to 12 for each rock formation) with an alternating gradient Magnetometer MICROMAG (made by Princeton Measurements Corporation, USA). For each sample the following parameters were determined: $H_{\mathrm{c}}$ - coercive force, $m_{\mathrm{s}}$ - saturation moment, $m r_{\mathrm{s}}$ - remanent saturation moment. Hysteresis loops were determined in a maximum field of $1 \mathrm{~T}$ (Fig. 1c, 2c).

\subsubsection{Mössbauer study}

The samples were ground to a fine powder. For 9 samples the Mössbauer spectra were measured at room temperature and for 2 additional ones at $77 \mathrm{~K}$ with a conventional Mössbauer spectrometer. A $30 \mathrm{mCi}{ }^{57} \mathrm{Co} / \mathrm{Rh}$ source was used. The drive velocity and isomer shifts were calibrated with an $\alpha$-Fe foil. The Mössbauer spectra of the rock samples were analysed by means of the Recoil [3] program. 

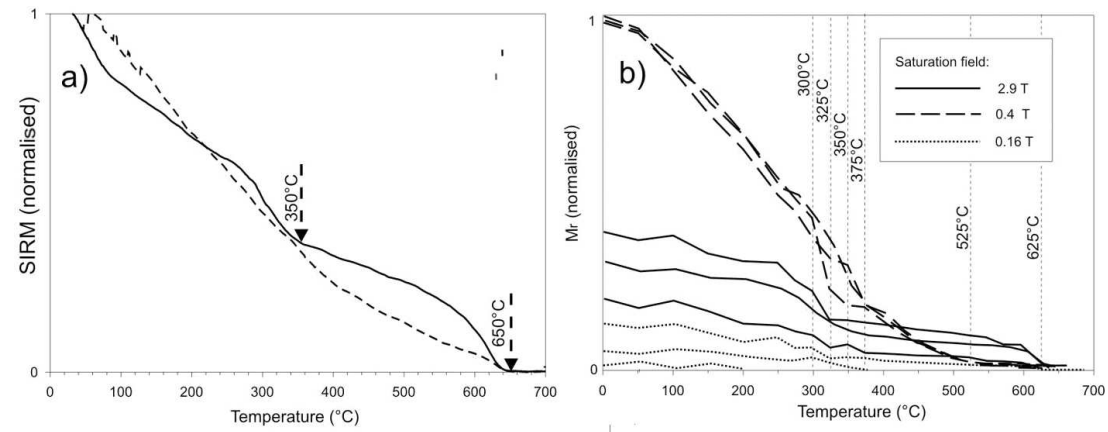

c)

d)
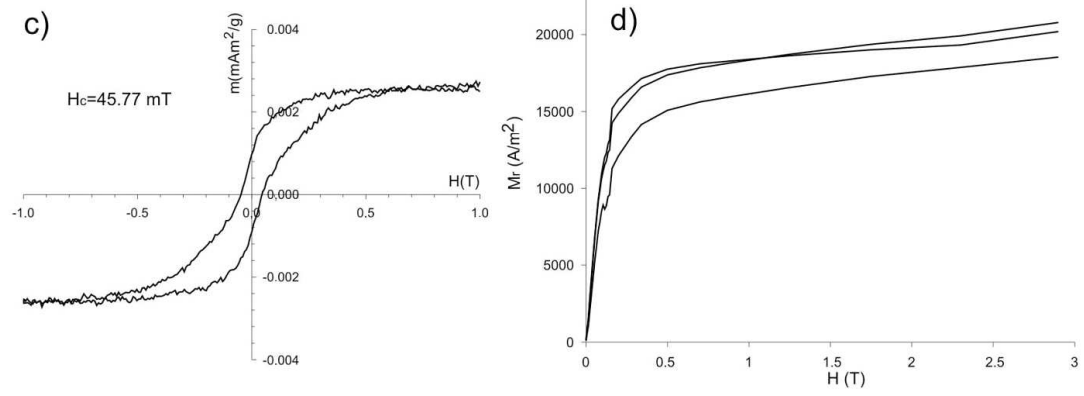

Fig. 2. Examples results of laboratory magnetic investigations for Cambrian Slaklidalen Fm: (a) decay curves of SIRM; (b) Lowrie test — visible domination of middle coercivity fraction; (c) hysteresis loop of distinct wasp-waist shape; (d) IRM curves — visible two ferromagnetic (sensu lato) fractions: first saturated below $0.2 \mathrm{~T}$ and the second not saturated below maximum applied field $2.9 \mathrm{~T}$; other abbreviations as in Fig. 1.

The uncertainties of the Mössbauer parameters are: $0.02 \mathrm{~mm} / \mathrm{s}$ for the isomer shift (IS), $0.03 \mathrm{~mm} / \mathrm{s}$ for the quadrupole splitting (QS), $0.5 \mathrm{~T}$ for the hyperfine magnetic field and $5 \%$ for determining the area.

\section{Results}

\subsection{Devonian sandstones of the Marietoppen Formation and Carboniferous sandstones of the Hyrnefjellet Formation}

\subsubsection{Magnetic measurements}

The majority of the magnetic experiments performed on both formations revealed domination of high coercivity minerals (IRM curves are saturated above 1.5 T - Fig. 1d, domination of a magnetic phase saturated above $0.4 \mathrm{~T}$ on the Lowrie diagrams - Fig. 1b) with maximum unblocking temperatures above $600^{\circ} \mathrm{C}$ - in most cases $680-690^{\circ} \mathrm{C}$ typical of hematite (Fig. 1a, b) [4]. In some specimens a rapid change of slope of the IRM curves below $0.2 \mathrm{~T}$ (Fig. 1d) and a wasp-waist shape of the hysteresis loops (Fig. 1c) suggest the presence of other ferromagnetic (sensu lato) minerals with lower coercivity, probably Fe/Ti oxides observed during microprobe analysis. 


\subsubsection{Mössbauer measurements}

The Mössbauer spectra obtained from selected samples are shown in Fig. 3. In all Mössbauer spectra a superposition of two doublets and one sextet is present. The first doublet has parameters typical of ferric iron, second - typical of ferrous iron.

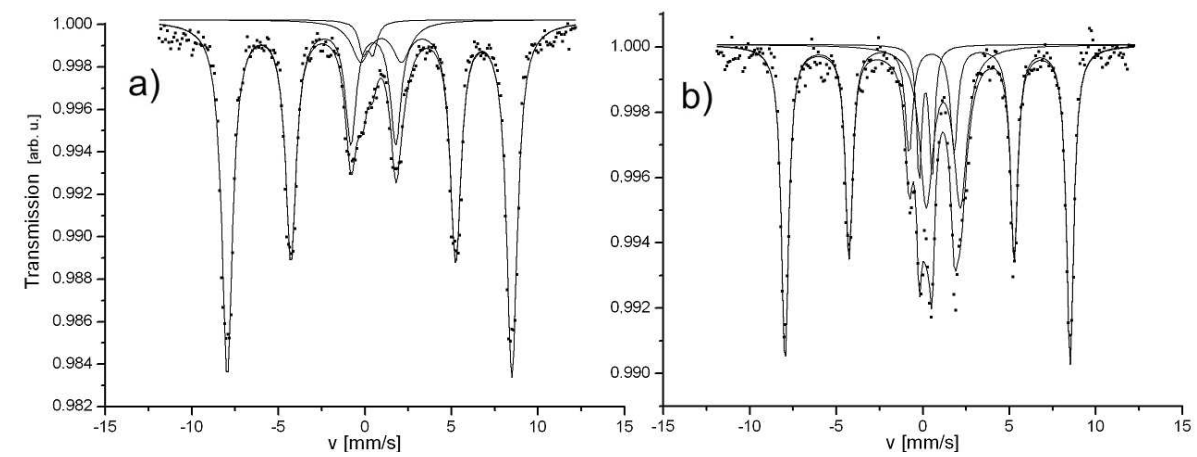

Fig. 3. Room temperature (RT) Mössbauer spectrum of Devonian sandstone sample 2.B (a) and RT Mössbauer spectrum of Carboniferous sandstone sample 3.C (b).

TABLE I

Mössbauer parameters of Devonian and Carboniferous sandstones obtained at RT.

\begin{tabular}{|c|c|c|c|c|c|c|c|}
\hline \multirow{2}{*}{$\begin{array}{l}\text { Rocks } \\
\text { formation }\end{array}$} & \multirow[t]{2}{*}{ Sample } & \multirow[t]{2}{*}{ Subspectrum } & \multicolumn{5}{|c|}{ Parameters } \\
\hline & & & $\begin{array}{c}\mathrm{IS} \\
{[\mathrm{mm} / \mathrm{s}]}\end{array}$ & $\begin{array}{c}\mathrm{QS} \\
{[\mathrm{mm} / \mathrm{s}]}\end{array}$ & $\begin{array}{c}H \\
{[\mathrm{~T}]}\end{array}$ & $\begin{array}{c}A \\
{[\%]}\end{array}$ & $\begin{array}{c}\Gamma / 2 \\
{[\mathrm{~mm} / \mathrm{s}]}\end{array}$ \\
\hline \multirow{6}{*}{ Marioetroppen } & \multirow{3}{*}{ 2.A } & $\mathrm{Fe}^{2+}$ & 1.20 & 2.50 & & 36 & 0.25 \\
\hline & & $\mathrm{Fe}^{3+}$ & 0.23 & 0.84 & & 34 & 0.28 \\
\hline & & hematite & 0.37 & -0.09 & 51 & 30 & 0.23 \\
\hline & \multirow{3}{*}{ 2.B } & $\mathrm{Fe}^{2+}$ & 1.14 & 2.59 & & 18 & 0.65 \\
\hline & & $\mathrm{Fe}^{3+}$ & 0.28 & 0.78 & & 11 & 0.29 \\
\hline & & hematite & 0.37 & -0.10 & 51 & 71 & 0.38 \\
\hline \multirow{9}{*}{ Hyrnetjellet } & \multirow{3}{*}{ 3.A } & $\mathrm{Fe}^{2+}$ & 1.18 & 1.97 & & 28 & 0.47 \\
\hline & & $\mathrm{Fe}^{3+}$ & 0.16 & 0.75 & & 9 & 0.18 \\
\hline & & hematite & 0.38 & -0.11 & 51 & 63 & 0.25 \\
\hline & \multirow{3}{*}{ 3.B } & $\mathrm{Fe}^{2+}$ & 0.94 & 2.36 & & 9 & 0.73 \\
\hline & & $\mathrm{Fe}^{3+}$ & 0.17 & 0.57 & & 3 & 0.20 \\
\hline & & hematite & 0.37 & -0.11 & 51 & 88 & 0.32 \\
\hline & \multirow{3}{*}{ 3. C } & $\mathrm{Fe}^{2+}$ & 0.91 & 2.56 & & 19 & 0.22 \\
\hline & & $\mathrm{Fe}^{3+}$ & 1.30 & 2.61 & & 25 & 0.41 \\
\hline & & hematite & 0.41 & -0.11 & 51 & 56 & 0.19 \\
\hline
\end{tabular}


Magnetic subspectra present in all samples were identified as hematite [5] $(H=51 \mathrm{~T}, \mathrm{IS}=0.37 \mathrm{~mm} / \mathrm{s}, \mathrm{QS}=-0.11 \mathrm{~mm} / \mathrm{s})$. The Mössbauer parameters of all samples are presented in Table I.

\subsection{Cambrian limestones of the Slaklidalen Formation}

\subsubsection{Magnetic measurements}

Magnetic experiments proved that Slaklidalen Fm specimens are composed of mixture of ferromagnetic (sensu lato) minerals with varying maximum unblocking temperatures $\left(T_{\mathrm{ub} \max }\right)$ and coercivities (Fig. 2$)$.

Three main ferromagnetic fractions have been identified: 1 . saturation fields $<0.4 \mathrm{~T}, T_{\mathrm{ub} \max }=525-550^{\circ} \mathrm{C}$ - probably magnetite, 2 . saturation fields $<$ and $>$ $0.4 T_{\mathrm{ub} \text { max }}=330-360^{\circ} \mathrm{C}-$ ferromagnetic sulphides (suggested also by microprobe analyses) or maghemite - undistinguished by applied magnetic experiments, 3 . saturation fields $>0.4 \mathrm{~T}, T_{\mathrm{ub}}=50-100^{\circ} \mathrm{C}$ and $625-650^{\circ} \mathrm{C}-$ probably goethite and hematite.

It is important to mention that the fraction with $T_{\mathrm{b}}=330-360^{\circ} \mathrm{C}$ is the carrier of the most stable and readable characteristic remanent magnetisation (ChRM). However, because of the relatively low signal of Slaklidalen samples and limitations of the applied magnetic methods, defining its exact ferromagnetic mineralogy is impossible.

\subsubsection{Mössbauer measurements}

The Mössbauer spectrum obtained from the 1.A sample is shown in Fig. 4. In the Mössbauer spectra recorded at room temperature only two doublets are

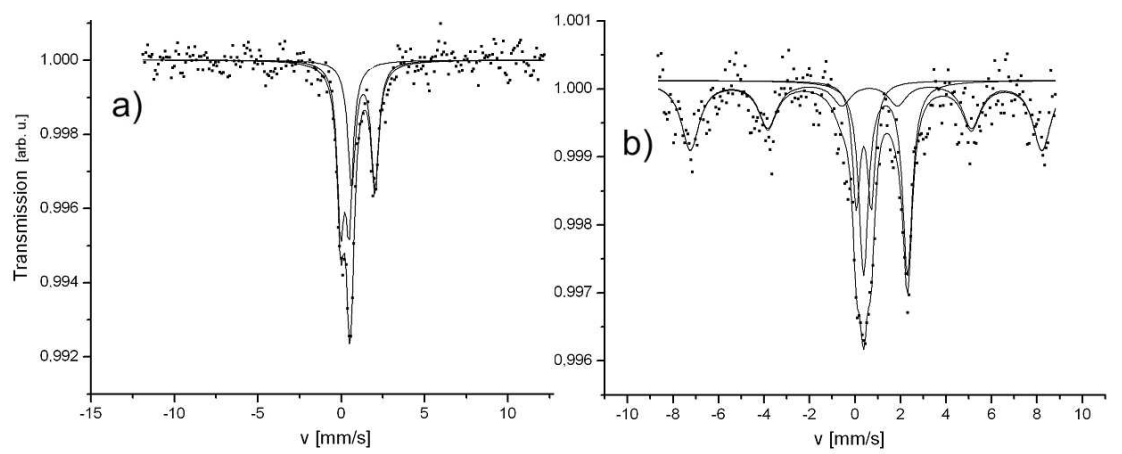

Fig. 4. RT mössbauer spectrum of the 1.A Cambrian limestones sample at $300 \mathrm{~K}$ (a) and $77 \mathrm{~K}(\mathrm{~b})$.

present. The first doublet has parameters typical of ferric iron, second - typical of ferrous iron. In the Mössbauer spectrum recorded at $77 \mathrm{~K}$ a magnetic subspectrum appears. This magnetic subspectrum could be identified as nanoparticles of maghemite [5]. In sample 1.B there are two more subspectra, however they are still unrecognised. The Mössbauer parameters of sample 1.A are presented in Table II and those of sample 1.B in Table III. 
TABLE II

Mössbauer parameters of sample 1.A taken from the Cambrian limestone.

\begin{tabular}{c|c|c|c|c|c|c}
\hline \hline & Subspectrum & $\begin{array}{c}\text { IS } \\
{[\mathrm{mm} / \mathrm{s}]}\end{array}$ & $\begin{array}{c}\text { QS } \\
{[\mathrm{mm} / \mathrm{s}]}\end{array}$ & $\begin{array}{c}H \\
{[\mathrm{~T}]}\end{array}$ & $\begin{array}{c}A \\
{[\%]}\end{array}$ & $\begin{array}{c}\Gamma / 2 \\
{[\mathrm{~mm} / \mathrm{s}]}\end{array}$ \\
\hline \multirow{2}{*}{$\mathrm{RT}$} & $\mathrm{Fe}^{2+}$ & 1.32 & 1.4 & - & 48 & 0.30 \\
& $\mathrm{Fe}^{3+}$ & 0.22 & 0.5 & - & 52 & 0.23 \\
\hline \multirow{3}{*}{$77 \mathrm{~K}$} & $\mathrm{Fe}^{2+}$ & 1.34 & 1.92 & - & 36 & 0.25 \\
& $\mathrm{Fe}^{3+}$ & 0.39 & 0.66 & - & 19 & 0.20 \\
& Sextet1 & 0.59 & & 48 & 36 & 0.36 \\
& Sextet2 & 0.50 & & 44 & 9 & 0.20
\end{tabular}

TABLE III

Mössbauer parameters of the 1.B sample taken from Cambrian limestones.

\begin{tabular}{c|c|c|c|c|c|c}
\hline \hline & Subspectrum & $\begin{array}{c}\text { IS } \\
{[\mathrm{mm} / \mathrm{s}]}\end{array}$ & $\begin{array}{c}\text { QS } \\
{[\mathrm{mm} / \mathrm{s}]}\end{array}$ & $\begin{array}{c}H \\
{[\mathrm{~T}]}\end{array}$ & $\begin{array}{c}A \\
{[\%]}\end{array}$ & $\begin{array}{c}\Gamma / 2 \\
{[\mathrm{~mm} / \mathrm{s}]}\end{array}$ \\
\hline \multirow{3}{*}{$\mathrm{RT}$} & $\mathrm{Fe}^{2+}$ & 1.29 & 1.91 & - & 20 & 0.24 \\
& $\mathrm{Fe}^{2+}$ & 1.08 & 1.48 & - & 15 & 0.16 \\
& $\mathrm{Fe}^{3+}$ & 0.33 & 0.77 & - & 65 & 0.38 \\
\hline \multirow{7}{*}{$77 \mathrm{~K}$} & $\mathrm{Fe}^{2+}$ & 1.36 & 1.90 & - & 40 & 0.21 \\
& $\mathrm{Fe}^{3+}$ & 0.36 & 0.73 & - & 24 & 0.21 \\
& Sextet1 & 0.50 & -0.11 & 48 & 19 & 0.25 \\
& Sextet2 & 0.48 & - & 46 & 11 & 0.18 \\
& Sextet3 & 0.49 & - & 42 & 5 & 0.17
\end{tabular}

\section{Discussion}

The Mössbauer and magnetic measurements performed for Devonian and Carboniferous formations indicate that in these rocks hematite dominates.

For samples taken from Cambrian formation there are some controversies about the carrier of the most stable ChRM. Basing on magnetic investigations only, we are not able to define its exact mineralogy - for the most stable ferromagnetic (sensu lato) fraction with wide range of coercivities and $T_{\mathrm{b}}=330-360^{\circ} \mathrm{C}$ (see point 2 in Sect. 3.2.1) both iron sulphides and maghemite are possible. The Mössbauer spectra of the Cambrian samples, obtained at RT and at $77 \mathrm{~K}$, may suggest that in these rocks nanoparticles of maghemite are present. For elucidation of these discrepancies further investigations are needed. Forming of hematite in Devonian and Carboniferous sandstones is probably related to early diagenesis of these formations. Maghemite in Cambrian limestones probably appeared during Caledonian remagnetisation event. 


\section{Acknowledgments}

This study is a part of palaeomagnetic project which mainly aims at the reconstruction of the palaeogeographic position of the northern part of the Barents Sea Platform (European Arctic) in the Palaeozoic and Mesozoic [6]. Samples were collected in the years 1999-2006 in the area of Hornsund, Southern Spits-
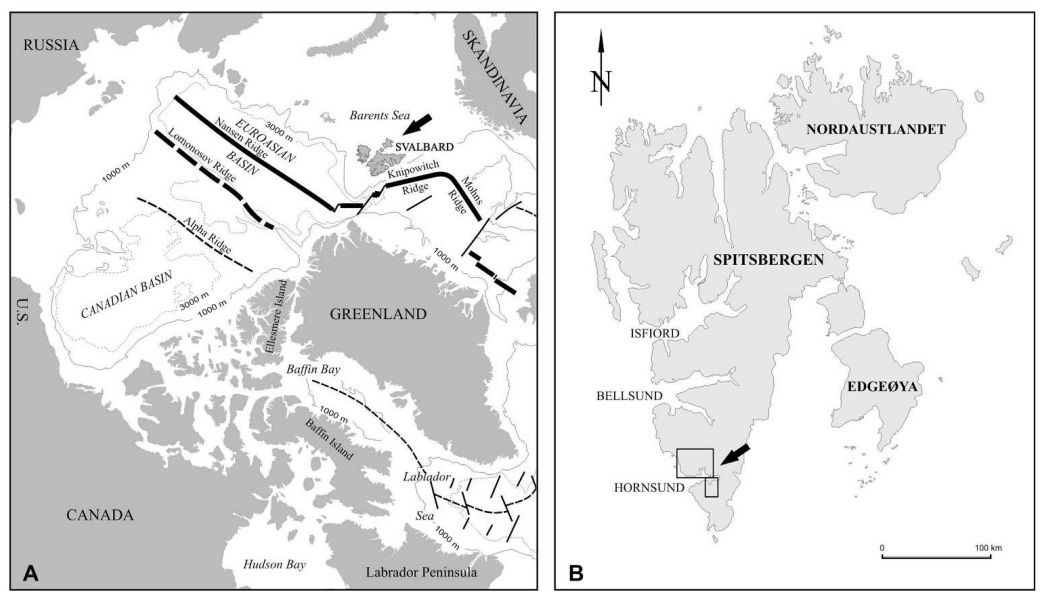

Fig. 5. Locations of the sampled areas. (A) Location of the Svalbard Archipelago in the present Arctic geotectonic system (marked by an arrow). (B) Contour map of the Svalbard Archipelago - investigated areas in vicinity of Hornsund are marked by squares.

bergen (Fig. 5), with support of the Polish Polar Station in Hornsund, Institute of Geophysics, Polish Academy of Sciences (IGF PAS). The field and laboratory investigations have been funded by IGF PAS and Polish Ministry of Science and Higher Education - grants 3 P04D 03725 and 2 P04D 04530.

\section{References}

[1] M. Kądziałko-Hofmokl, J. Kruczyk, Pure Appl. Geophys. 110, 2031 (1976).

[2] W. Lowrie, Geophys. Res. Lett. 17, 159 (1990).

[3] http://www.science.uottawa.ca/recoil/.

[4] D.J. Dunlop, Ö. Özdemir, Rock Magnetism Fundamentals and Frontiers, Cambridge University Press, Cambridge 1997, p. 1.

[5] J.G. Stevens, A.M. Khasanov, J.W. Miller, H. Pollak, Z. Li, Mössbauer Mineral Handbook, Mössbauer Effect Data Center, Asheville 1998, p. 297, 339.

[6] K. Michalski, M. Lewandowski, Pol. Polar Res. 25, 169 (2004). 